\title{
Urban expansion and its consumption of high-quality farmland in Beijing, China
}

\author{
Wei Song ${ }^{\mathrm{a}, *}$, Bryan C. Pijanowski ${ }^{\mathrm{b}}$, Amin Tayyebi ${ }^{\mathrm{b}, \mathrm{c}}$ \\ ${ }^{a}$ Key Laboratory of Land Surface Pattern and Simulation, Institute of Geographic Sciences and Natural Resources Research, Chinese Academy of Sciences, \\ 11A, Datun Road Chaoyang District, Beijing, 100101, People's Republic of China \\ ${ }^{\mathrm{b}}$ Department of Forestry and Natural Resources, Purdue University, West Lafayette, Indiana 47906, USA \\ ${ }^{c}$ University of Wisconsin-Madison, Wisconsin Energy Institute, 1552 University Avenue, Madison, WI 53726, USA
}

\section{A R T I C L E I N F O}

\section{Article history:}

Received 16 February 2014

Received in revised form 5 February 2015

Accepted 10 February 2015

\section{Keywords:}

Urban expansion

High-quality farmland

Land evaluation

Land transformation model

Beijing

\begin{abstract}
A B S T R A C T
China faces the challenge of using limited farmland to feed more than 1.3 billion people. Accelerated urbanization has exacerbated this challenge by consuming a large quantity of high-quality farmland (HQF). It is therefore essential to assess the degree to which urban expansion has preferentially consumed $\mathrm{HQF}$, and discern the mechanism behind this. We found urban areas in Beijing to expand at speeds of $48.97 \mathrm{~km}^{2} /$ year, $21.89 \mathrm{~km}^{2} /$ year, $62.30 \mathrm{~km}^{2} /$ year and $20.32 \mathrm{~km}^{2} /$ year during the periods $1986-1995$, 1995-2000, 2000-2005 and 2005-2020, respectively. We developed an indicator of HQF consumption due to urban expansion, representing the ratio of HQF consumed to its proportion of overall farmland, and found its values were 2.21, 1.57, 1.99 and 1.10 for 1986-1995, 1995-2000, 2000-2005 and 2005-2020, respectively. Thus, although HQF has been overrepresented in the farmland consumed by Beijing's urbanization, this phenomenon has decreased over time. Centralized expansion has contributed greatly to consumption of HQF. Topography and distances to urban and water bodies determine the relative consumption of $\mathrm{HQF}$ in urbanization.
\end{abstract}

(C) 2015 Elsevier Ltd. All rights reserved.

\section{Introduction}

Urbanization is regarded as a necessary phase in a country's journey toward modernization (He et al., 2006; Song et al., 2012; Shahbaz et al., 2014; Wang et al., 2014). According to a forecast by the United Nations (2012), the urban proportion of world population is projected to be $67.2 \%$ in 2050 . Urbanization inevitably results in the expansion of urban area; for example, the total global urban area quadrupled during 1970-2000 (Seto et al., 2011). Urban areas in developing countries are projected to increase from to $300,000 \mathrm{~km}^{2}$ in 2000 to $770,000 \mathrm{~km}^{2}$ in 2030 , and $1,200,000 \mathrm{~km}^{2}$ in 2050 (Angel et al., 2011). As the biggest developing country, China has been on the track of rapid urbanization since the implementation of its Reform and Opening-Up Policy in 1978. The proportion of urban population in China has increased to $47.5 \%$ in 2010 from $22.9 \%$ in 1985 (Jiang et al., 2012). This trend is likely to continue for several decades.

Although urban areas account for only about four percent of the Earth's land surface area, urban expansion has significantly

\footnotetext{
* Corresponding author. Tel.: +86106488 9450.

E-mail address: songw@igsnrr.ac.cn (W. Song).
}

changed the natural landscape and generated enormous environmental and social impacts (Lee and Choe, 2011; Tang, 2011; Van Delm and Gulinck, 2011; Su et al., 2014). For example, urban expansion usually results in habitat loss (Sala et al., 2000), fragmentation (Batisani and Yarnal, 2009; Song, 2014; Song and Liu, 2014), resource removal (Rebele, 1994) and the decrease of native biodiversity (Su et al., 2011; Seto et al., 2012). In addition, the urbanization process can also result in degradation of air and water quality (Guttikunda et al., 2003; Van Metre and Mahler, 2005; Wang et al., 2013) and affect public health (Khoo et al., 2003). Therefore, scientific awareness of the negative consequences of urbanization is increasing.

Farmland loss is one major consequence of urban expansion. Farmland is particularly precious for China because of its huge population and scarce land per capita (Tan et al., 2005; Song and Pijanowski, 2014). In the past three decades, China's farmland has experienced a sharp decrease in area, which has threatened the country's food security (Kim et al., 2003; Tan et al., 2005; Zhong et al., 2011; Song and Pijanowski, 2014). Among the drivers of farmland loss, urban expansion has been especially important. During 1986-2003, urban expansion in China occurred on more than $33,400 \mathrm{~km}^{2}$ of farmland, accounting for $21 \%$ of total farmland loss (Chen, 2007). Much recent research has examined the 


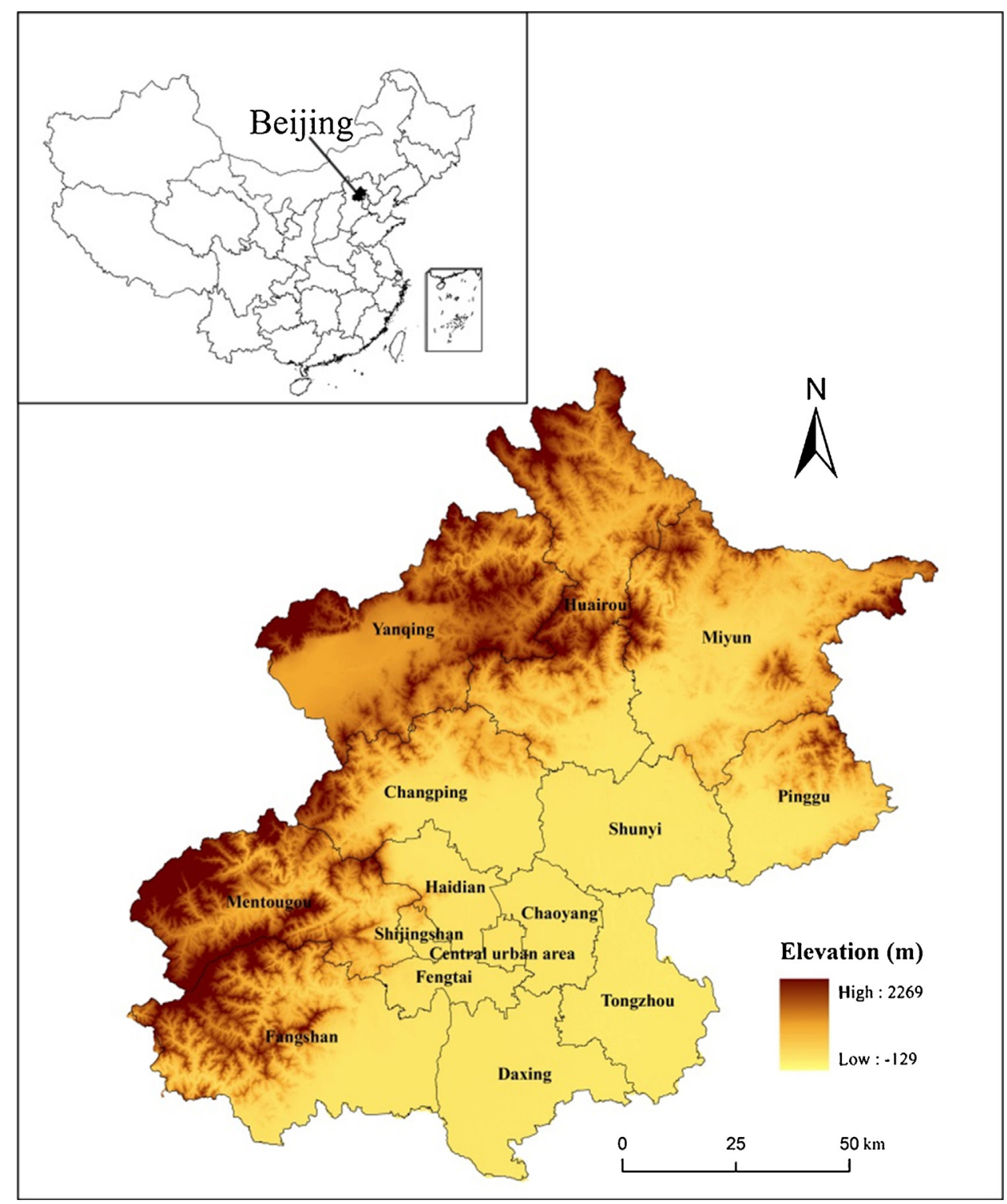

Fig. 1. Beijing's location in China and elevations of areas within Beijing.

characteristics of urban expansion and the consequent farmland loss in different regions (Verburg et al., 1999; Batisani and Yarnal, 2009; Deng et al., 2010; Jiang et al., 2012; Kong et al., 2012; Lu et al., 2011) However, less attention has been paid to the quality of farmland lost through urban expansion. In particular, no quantitative indicator of high-quality farmland (HQF) consumption due to urbanization has been developed. Additionally, the factors influencing whether urban expansion preferentially consumes HQF has not been fully elucidated. These gaps have made it difficult for planners to assess the effects of urban expansion patterns on farmland quality.

In view of the inevitability of urban expansion in China over the next two decades, assessing and predicting HQF losses due this expansion are of particular importance. In the present study, we seek to do this for Beijing. To accomplish this, we develop an indicator linking urban expansion with HQF consumption and to also identify the factors that influence this linkage. Our specific aims are to: (1) determine the spatiotemporal pattern of urban expansion during the past two decades and next two decades in Beijing;
(2) develop and apply an indicator of the relative consumption of HQF through this expansion and (3) discern the factors influencing consumption of HQF by urban expansion.

\section{Study area and data sources}

\subsection{Study area}

Beijing, the capital of China, is located between $39^{\circ} 38^{\prime} \mathrm{N}-40^{\circ} 51^{\prime}$ and $115^{\circ} 25^{\prime} \mathrm{N}-117^{\circ} 30^{\prime}$, and covers an area of $16,410.54 \mathrm{~km}^{2}$; mountains account for $58.78 \%$ and plains $41.22 \%$ of this area. The mountains are mainly to the north-west with an average elevation of about $1000-1500 \mathrm{~m}$, and the plains are mostly in the center and south-east of the city, with an elevation ranging from $20 \mathrm{~m}$ to $60 \mathrm{~m}$. (Fig. 1) The climate of Beijing is sub-humid warm temperate continental monsoon, but the winter is cold and dry. The average temperature is around $13.1^{\circ} \mathrm{C}$, and precipitation is about $430.9 \mathrm{~mm}$ annually. 
Table 1

Scores for each particular indicator value in assessment.

\begin{tabular}{|c|c|c|c|c|c|c|}
\hline \multirow[b]{2}{*}{ Score } & \multicolumn{4}{|l|}{ Soil conditions } & \multirow{2}{*}{$\frac{\text { Topography }}{\text { Slope }\left(^{\circ}\right)}$} & \multirow{2}{*}{$\begin{array}{l}\text { Water condition } \\
\text { Irrigation guarantee rate }\end{array}$} \\
\hline & Soil texture & Effective soil thickness (cm) & Soil organic matter & Soil profile & & \\
\hline 100 & Heavy loam & $\geq 150$ & $\geq 4.0$ & Grade 1 & $\leq 2$ & Fully satisfied \\
\hline 90 & Clay & $100-150$ & $3.0-4.0$ & Grade 2 & $2-5$ & \\
\hline$>" 80$ & Medium loam & & $2.0-3.0$ & Grade 3 & $5-8$ & Basically satisfied \\
\hline 70 & Light loam & $60-100$ & $1.0-2.0$ & Grade 4 & & \\
\hline 60 & Sandy loam & & $0.6-1$ & Grade 5 & $8-15$ & Generally satisfied \\
\hline 50 & Sandy soil & & $\leq 0.6$ & Grade 6 & & \\
\hline 40 & Gravel soil & $30-60$ & & Grade7 & & No irrigation condition \\
\hline 30 & & & & & $15-25$ & \\
\hline \multicolumn{7}{|l|}{20} \\
\hline 10 & & & & & $\geq 25$ & \\
\hline Weight & 0.13 & 0.15 & 0.08 & 0.12 & 0.22 & 0.30 \\
\hline
\end{tabular}

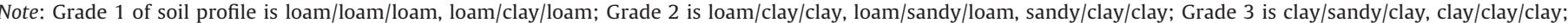
Grade 4 is gravel/clay/gravel; Grade 5 is loam/sandy/sandy; Grade 6 is clay/sandy/sandy; and Grade 7 is sandy/sandy/sandy, gravel/gravel/gravel.

\subsection{Data sources}

Our analysis of urban expansion in Beijing relied on four landuse maps at 1:100,000 scale. These maps were derived from historical Landsat TM (Thematic Mapper) satellite images which were acquired in 1986, 1995, 2000 and 2005 by the China National Environmental Monitoring Center (Liu et al., 2005). The LULC maps were first divided into six primary classes: cultivated land, woodlands, grasslands, water bodies, construction land and unused land, and then further divided into 25 sub-classes.

In addition to these LULC maps, we also employed four other maps, of soil, DEM (Digital Elevation Model), roads and water bodies. The soil map, with a scale of $1: 100,000$, utilized to evaluate farmland quality was based on a soil survey performed in the $1980 \mathrm{~s}$. The soil map includes attributes of soil texture, effective soil thickness, soil organic matter, soil type, and soil parent material, among others. The DEM was sourced from the International Scientific Data Service Platform, with a resolution of $30 \mathrm{~m}$. The road map of Beijing was acquired from the Beijing Municipal Commission of Transport. The river and lake map of Beijing was derived from the Beijing Water Authority.

\section{Methods}

\subsection{Evaluation of farmland quality}

Land quality is a measure of the land's ability to perform specific functions (Beinroth et al., 2001; Eswaran et al., 2003). In the context of this study, we aimed to assess the quality of farmland, with its function being sustainable crop production. Various indices of farmland quality have been designed, including that of Eswaran et al. (2003), which focused on soil attributes. Here, however, we choose to employ an approach more similar to Liu et al. (2010), who developed a more comprehensive land quality assessment system based not only on soil quality, but also other land attributes including, e.g., slope, water availability, land use, topographic setting, land degradation risk, moisture and vegetation growing conditions. This approach is premised on idea that land quality reflects the complex association of soil, terrain, water, climate and biotic resources that characterize a location on the earth's surface.

For our study, we chose to use six land quality indicators that are included in China's Agricultural Land Classification and Gradation (ALCG) (MLRC, 2003). The ALCG draws on land quality evaluation studies completed by the FAO $(1977,1997)$ and others (Dumanski, 1997; Dumanski and Pieri, 2000; Beinroth et al., 2001; Eswaran et al., 2003; Liu et al., 2010). Our selection of these six was based on data availability, previous research on land quality and the recommendations by the MLRC (2003) for indicators of land quality in Beijing. Our assessment of indicator values and assignment of overall quality scores referenced the rules of the ALCG (MLRC, 2003) (Table 1).

Therefore, using these six indicators, farmland quality in Beijing can be assessed using the following equation:

$\mathrm{LQ}=\sum_{i=1}^{6} w_{i} \times \operatorname{In}_{i}$

where, LQ is the score of farmland quality; $i$ is the number of indicators, ranging from 1 to $6 ; w_{i}$ is the weight of indicator $i$; and $\operatorname{In}_{i}$ is the score of indicator $i$ (Table 1). A higher LQ score means a higher land quality of farmland.

Based on LQ values, we can identify HQF by using the following equation:

$\mathrm{FQR}=\frac{\mathrm{LQ}_{p}}{\mathrm{LQ}_{a}}$

where, $\mathrm{FQR}$ is the farmland quality rank; $\mathrm{LQ}_{p}$ is the land quality score of $p$ parcel; and $\mathrm{LQ}_{a}$ is the average quality score of total farmland. FQR in Beijing is approximately normally distributed. Based on the two inflection points in the normal distribution, we assigned the classifications "low", "medium", and "high" to FQR with the ranges $0-0.8,0.8-1.2$ and $1.2+$, respectively. Thus, HQF truly represents the highest quality farmland as assessed by our scoring and ranking system.

When assessing land quality, we considered the stability of the indicators. The characteristic response time (CRT) of the six

Table 2

Proportions of land quality ranks consumed by urban expansion in Beijing during 1986-2020.

\begin{tabular}{|c|c|c|c|c|}
\hline & 1986-1995 & 1995-2000 & 2000-2005 & 2005-2020 \\
\hline Proportion of low-quality farmland & 8.17 & 11.80 & 7.65 & 9.07 \\
\hline Proportion of medium-quality farmland & 70.93 & 73.36 & 73.57 & 80.50 \\
\hline Proportion of high-quality farmland & 20.90 & 14.84 & 18.79 & 10.43 \\
\hline $\mathrm{IHC}$ & 2.21 & 1.57 & 1.99 & 1.10 \\
\hline
\end{tabular}




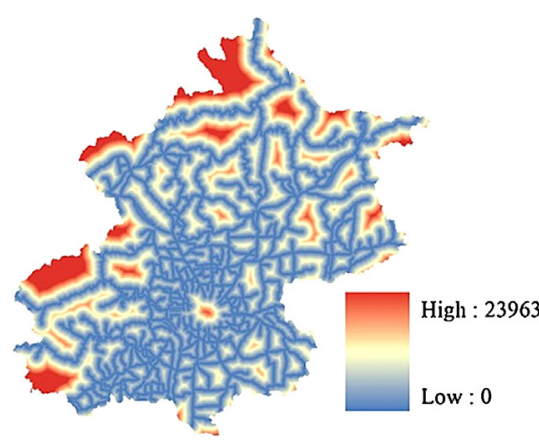

Distance from roads

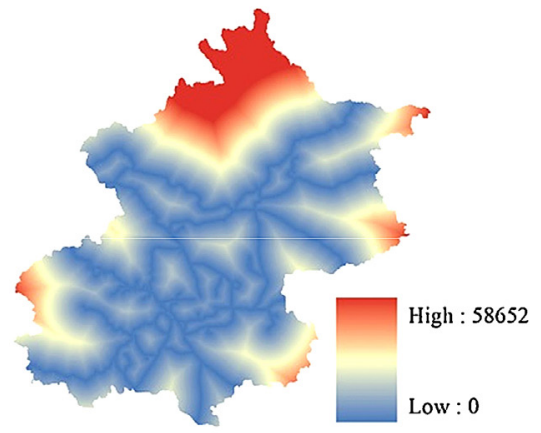

Distance from railways

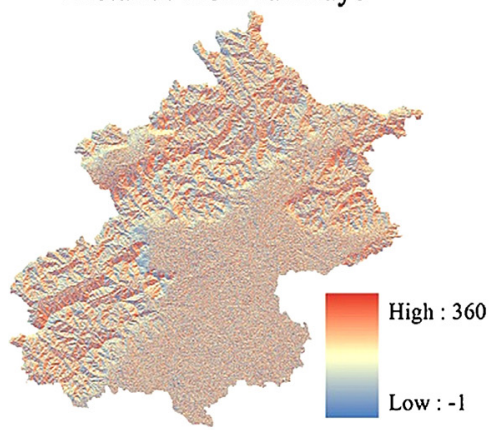

Aspect

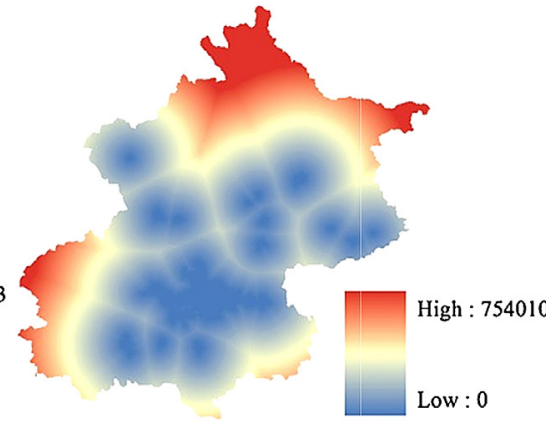

Distance from urban areas

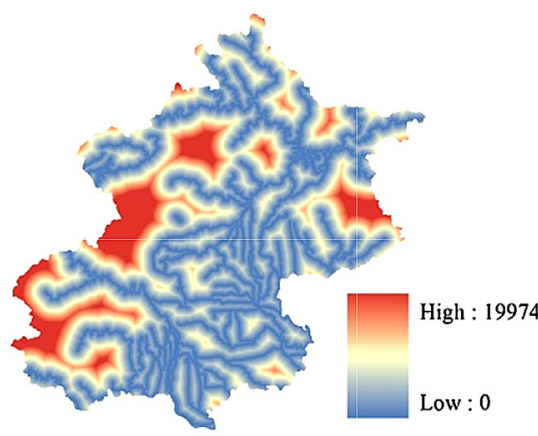

Distance from rivers

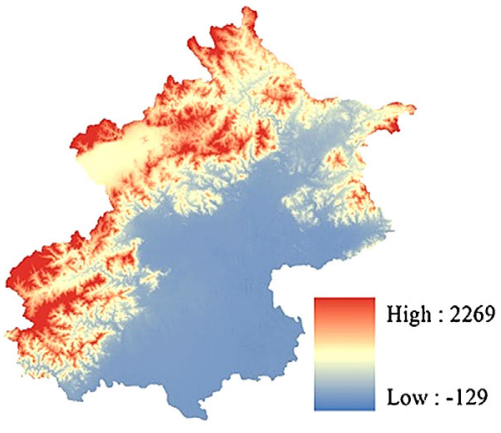

Elevation

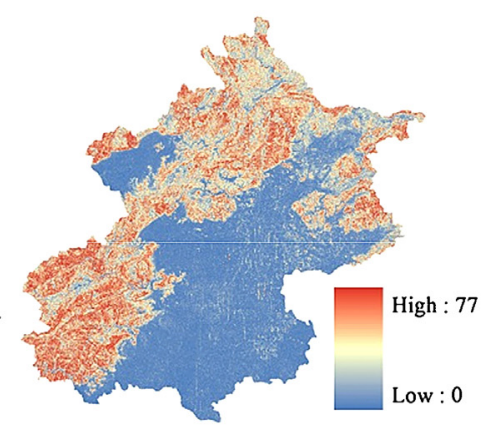

Slope

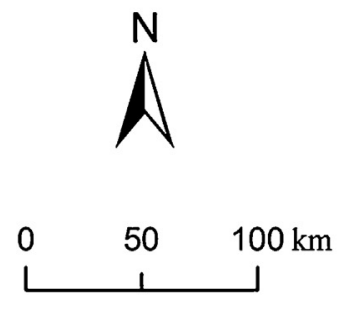

Fig. 2. Maps of the six variables used as input for ANN in 1986 in Beijing.

indicators usually ranges from $10^{1}$ year to $10^{3}$ year (Targulian and Krasilnikov, 2007; Chen et al., 2011). In other words, absent drastic interference by human activity (such as flattening the topography or moving soils), the values of the six indicators are likely to remain stable over several decades, meaning that the soil map and land quality data from the 1980 s should still be valid now.

\subsection{An indicator for monitoring the consumption of $\mathrm{HQF}$ by urban expansion}

We developed a quantitative indicator to assess the consumption of HQF by urban expansion on the basis of farmland quality evaluation:

$$
\begin{aligned}
& \mathrm{IHC}=\frac{\mathrm{PH}_{\mathrm{ue}}}{\mathrm{PH}_{\mathrm{wl}}} \\
& \mathrm{PH}_{\mathrm{ue}}=\frac{\mathrm{UE}_{\text {high }}}{\mathrm{UE}_{\text {whole }}} \\
& \mathrm{PH}_{\mathrm{wl}}=\frac{\mathrm{TF}_{\text {high }}}{\mathrm{TF}_{\text {whole }}}
\end{aligned}
$$

where, IHC is the indicator of HQF consumption by urban expansion; $\mathrm{PH}_{\mathrm{ue}}$ is the proportion $\mathrm{HQF}$ forms of total farmland lost to urban expansion; $\mathrm{PH}_{\mathrm{wl}}$ is the proportion $\mathrm{HQF}$ forms of total farmland; $\mathrm{UE}_{\text {high }}$ is the area of HQF consumed by urban expansion; $\mathrm{UE}_{\text {whole }}$ is the total area of farmland consumed by urban expansion; $\mathrm{TF}_{\text {high }}$ is the area of total HQF in the study area; $\mathrm{TF}_{\text {whole }}$ is the total farmland area in the study area.

If IHC is higher than 1 , it means that urban expansion preferentially consumes HQF, with the higher the IHC, the stronger this preference.

\subsection{Simulation of urban expansion}

The increasing recognition of the need for spatially-explicit land-use models has resulted in the development of diverse landuse change models (Turner, 1994; Verburg et al., 2002; Kong et al., 2012), e.g., Clue, SLEUTH, CUF, DELTA, Land Transformation Model (LTM), LUCAS, UPLAN and multi-agent-based models. In this paper, we employed the LTM, which couples geographic information systems (GIS) with artificial neural networks (ANNS) to forecast urban expansion. The LTM relies on information derived from historical analysis of land use and is a desktop computer application. Detailed descriptions of it can be found elsewhere (Pijanowski et al., 2002, 2005, 2009).

A large body of research has found the primary physical determinants of the locations occupied by urban expansion to be slope, 


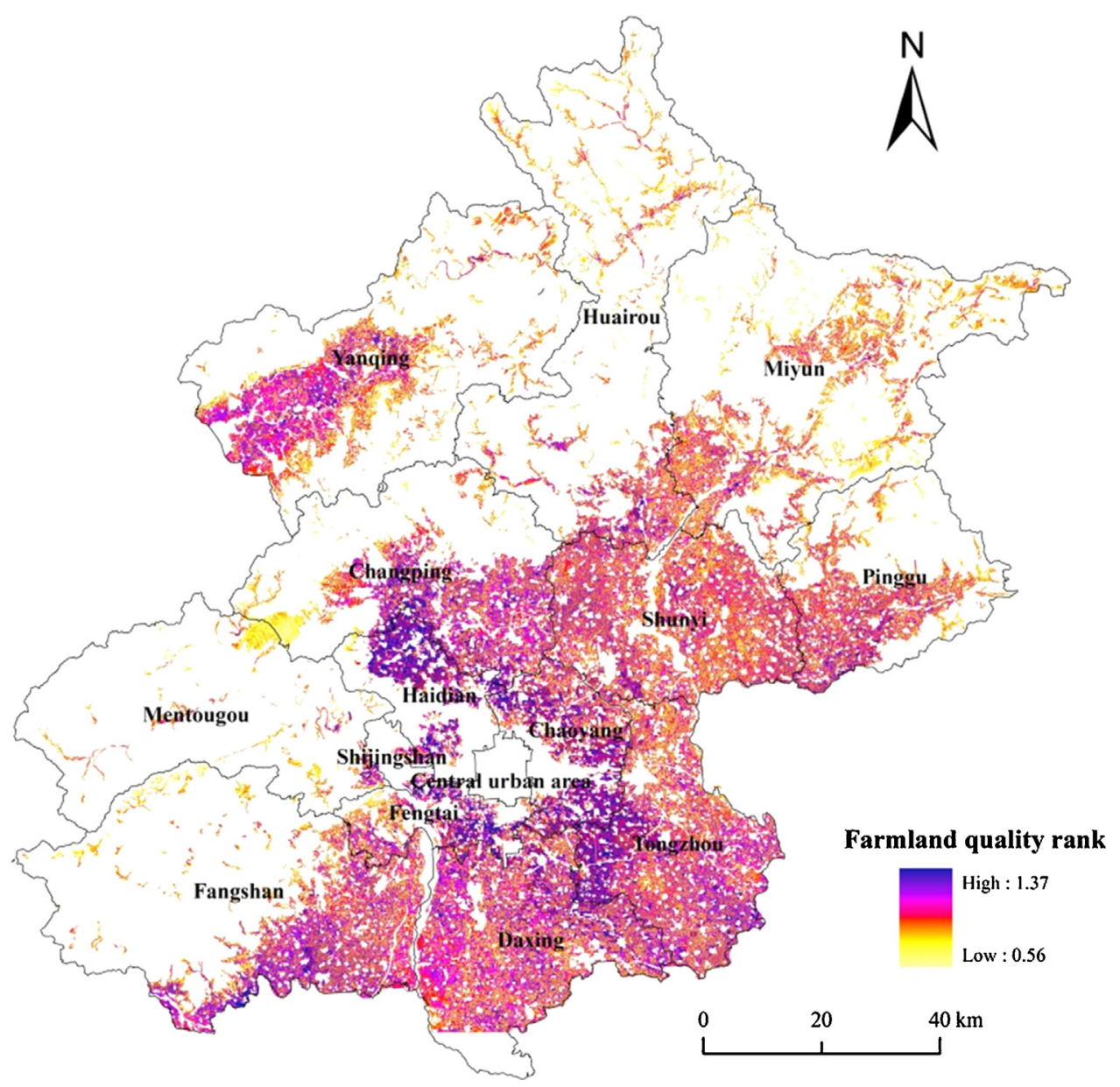

Fig. 3. Evaluation results of farmland quality in 1986

elevation, aspect (Wu and Yeh, 1997; Aspinall, 2004; He et al., 2006; Batisani and Yarnal, 2009; Dubovyk et al., 2011) and distance to water bodies (Cheng and Masser, 2003; Aspinall, 2004; Batisani and Yarnal, 2009). Elevation should be important in a local landscape that is prone to flooding (Pijanowski et al., 2009). Slope and aspect are important to developers in limiting landscaping costs. Fresh water bodies can serve as water sources and can also provide transportation functions for cities. Therefore, distance to water areas is a vital factor determining urban expansion (Pijanowski et al., 2002, 2005, 2009). Distances to road and railway have been identified by many studies as two vital socioeconomic factors influencing the expansion of urban areas (Cheng and Masser, 2003; Hu and Lo, 2007; He et al., 2006; Batisani and Yarnal, 2009; Pijanowski et al., 2009; Dubovyk et al., 2011). These two factors represent the potential accessibility of a location for new urban development. The distance to a city or suburban center is also a significant factor (Cheng and Masser, 2003; Aspinall, 2004; Batisani and Yarnal, 2009; Dubovyk et al., 2011; Ye et al., 2013), which could reflect the distance between housing and the greatest concentration of employment opportunities for the metropolitan area.

Other factors identified as having important effects include distance to airport, and presence of zoning regulations and conservation areas. However, based on data availability, we chose to use six factors in our simulation of Beijing urban expansion, i.e. slope, aspect, elevation, distance to road, distance to railway, distance to urban and distance to rivers (Fig. 2). All input GIS layers were created using $30 \times 30 \mathrm{~m}^{2}$ grid cells and served as the base data layer to the LTM for predicting present and future land use in Beijing. When simulating future urban expansion of Beijing, urban land as of 1986 and rivers, were coded as exclusionary zones so that they would not undergo transitions.

To enable the LTM to have adequate predictive capacity, we used different input data to train and test the ANN. Training involves presenting input values and adjusting the weights applied at each node according to the learning algorithm of back-propagation (Pijanowski et al., 2002, 2014). In this project, we trained ANNs using the actual urban changes between 1986 and 2005. To avoid over-training and reduce over-fitting, the grids in a cycle were first presented to the network in random order. We created 2927.5 $\mathrm{km}$ boxes and randomly chose 25 of them for use in training the ANNs by using actual input data in the random boxes. After then using the trained LTM to simulate land use changes in the rest of the boxes (267), we compared the simulated outcomes with the actual outcomes in these boxes to calculate the error rate.

Testing was finished by calculating the index of Percent Correct Metric (PCM), which could be expressed as follows:

$\mathrm{PCM}=\mathrm{TP} / \mathrm{TT}$

where, TP is the number of cells having changes that are correctly predicted; and TT is the total number of cells that have undergone changes during the research period.

\section{Results}

\subsection{Distribution of $\mathrm{HQF}$}

The areas of high-, medium- and low-quality farmland in Beijing in 1986 were $547.60 \mathrm{~km}^{2}, 4488.32 \mathrm{~km}^{2}$ and $764.57 \mathrm{~km}^{2}$ 

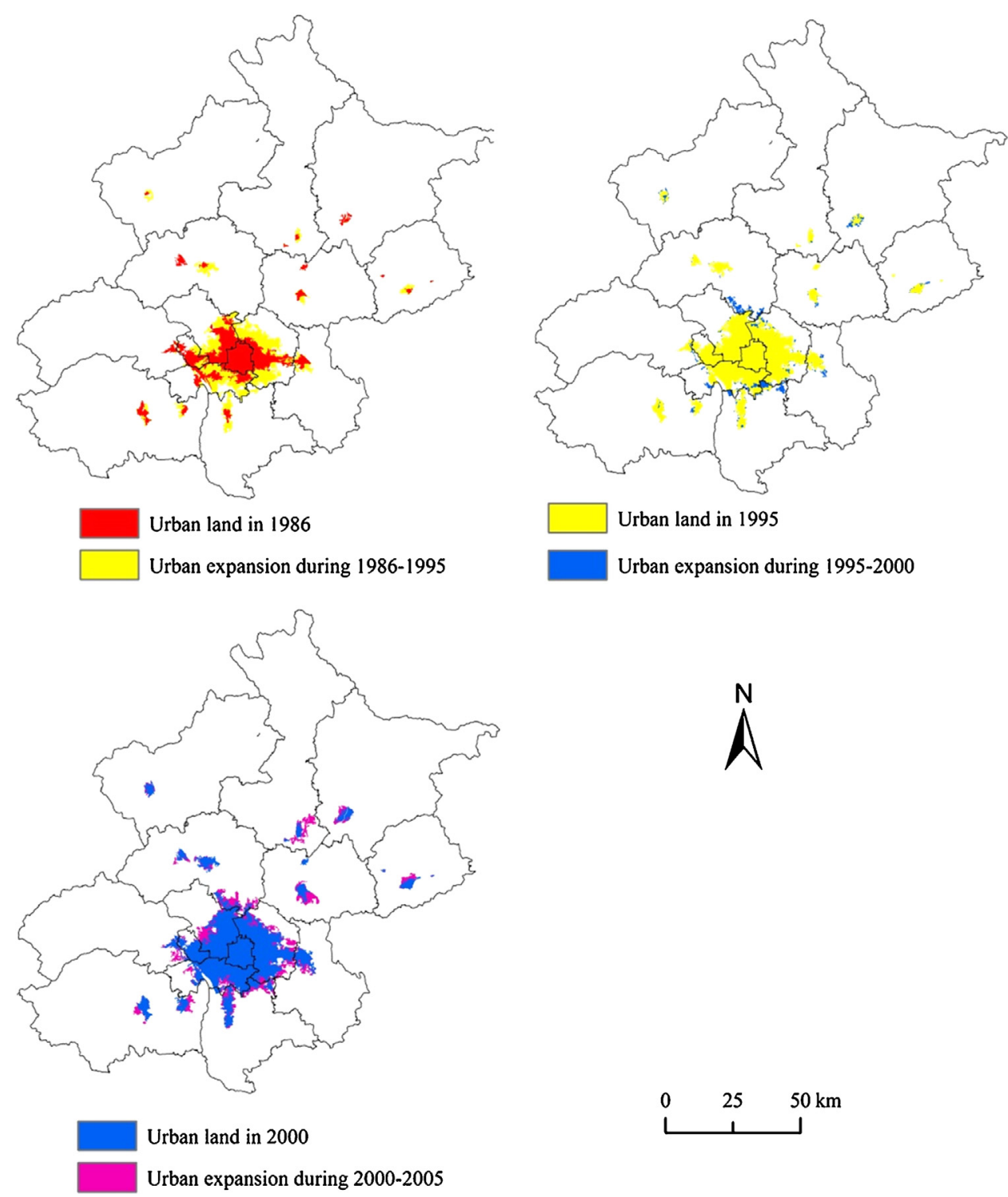

Urban expansion during 2000-2005

Fig. 4. Urban expansion during periods 1986-1995, 1995-2000 and 2000-2005 in Beijing.

respectively, contributing $9.44 \%, 77.38 \%$ and $13.18 \%$ to the total farmland, respectively. The HQF was mainly distributed in suburban Chaoyang $\left(78.06 \mathrm{~km}^{2}\right)$, Haidian $\left(61.26 \mathrm{~km}^{2}\right)$, Fengtai $\left(35.31 \mathrm{~km}^{2}\right)$ and outer suburban Daxing $\left(62.05 \mathrm{~km}^{2}\right)$ and Tongzhou $\left(76.91 \mathrm{~km}^{2}\right)$ (see Fig. 3). However, the ratio of HQF to total farmland decreased progressively from the inner to the outer suburbs. The proportions of HQF in Chaoyang, Haidian, Shijingshan and Fengtai were $27.97 \%, 36.97 \%, 14.68 \%$ and $21.17 \%$, respectively. The proportions of HQF in Miyun, Yanqing, Huairou and Mentougou were much lower: $1.02 \%, 5.10 \%, 4.41 \%$ and $3.83 \%$, respectively.

\subsection{Urban expansion in Beijing during 1986-2005}

The urban area of Beijing expanded from $483.56 \mathrm{~km}^{2}$ in 1986 to $1345 \mathrm{~km}^{2}$ in 2005 with a rate of $45.35 \mathrm{~km}^{2} /$ year. Over the past 19 years, the process of urban growth in Beijing experienced some high- and low-speed stages (Fig. 4). During the first stage (1986-1995), urban areas grew fast, at $48.97 \mathrm{~km}^{2} /$ year. Most of the urban expansion occurred in Chaoyang, Fengtai and Haidian, which accounted for $31.71 \%, 22.97 \%$ and $14.26 \%$ of the total urban expansion, respectively. In contrast, the urban expansion in Mentougou, Miyun, Huairou, Shunyi and Yanqing each contributed less than $2 \%$ of the total.

During the second stage (1995-2000), urban areas expanded at a speed of $21.89 \mathrm{~km}^{2} /$ year. Urban expansion during this period mainly occurred in Daxing, Changping, Chaoyang and Miyun, which accounted for $24.04 \%, 17.35 \%, 13.99 \%$ and $10.26 \%$ of total urban expansion, respectively. Thus, the urban expansion was largely in exurban rather than suburban districts. The urban area expanded slowly in Shijingshan, Huairou, Haidian, Pinggu, Shunyi and Mentougou, with none accounting for more than $3 \%$ of the total urban expansion. During the third stage (2000-2005), expansion sped up again, with urban areas expanding at $62.30 \mathrm{~km}^{2} /$ year. Urban expansion mostly occurred in Chaoyang, Changping and Daxing, accounting for $19.87 \%, 15.65 \%$ and $13.80 \%$ of the total, respectively. In comparison, urban areas in Shijingshan (0.00\%), Yanqing (1.16\%), Mentougou (3.46\%) and Pinggu (3.93\%) expanded rather slowly. 


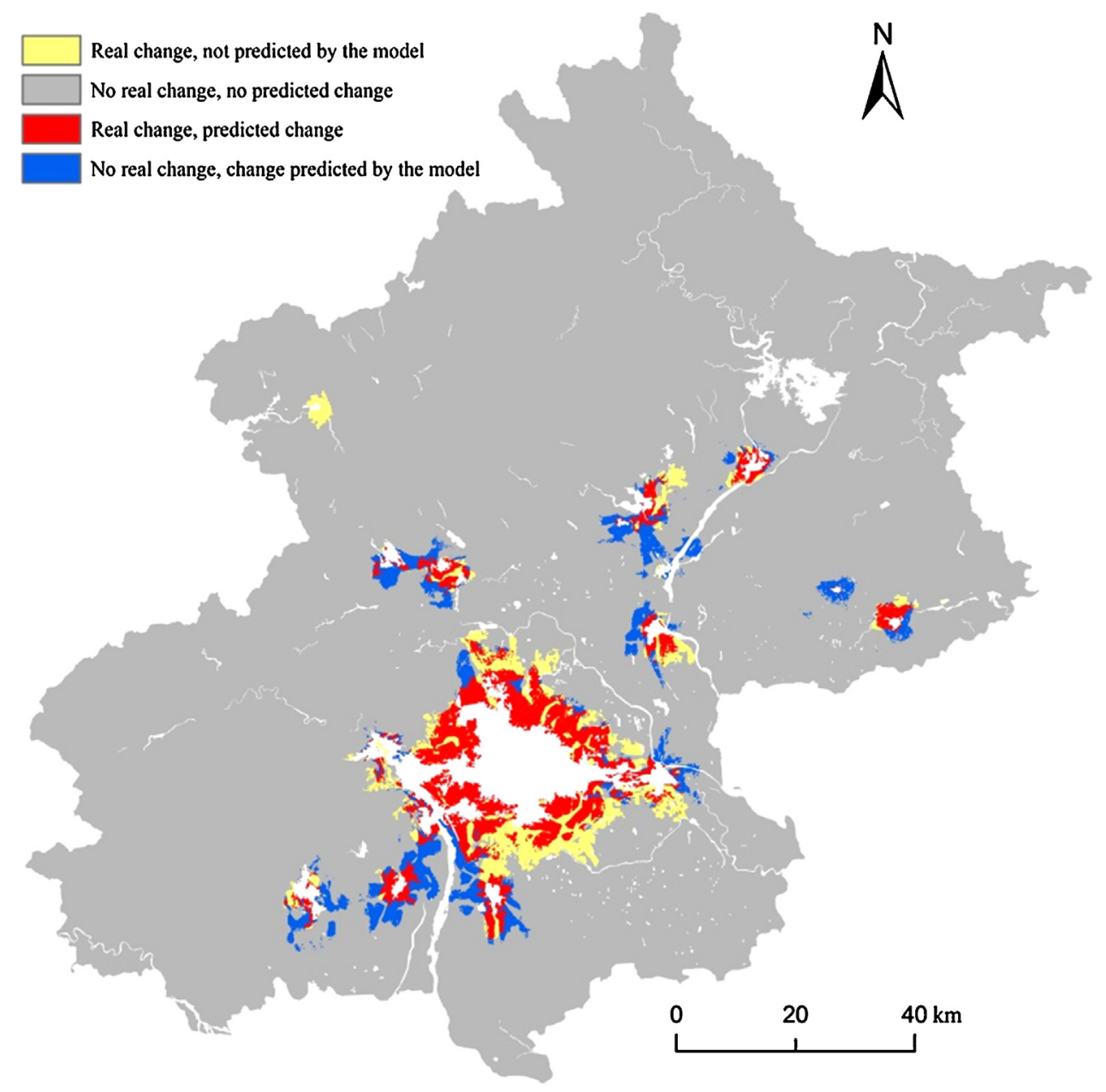

Fig. 5. Simulation results of urban expansion during 1986-2005 in Beijing.

\subsection{Simulation and forecast of Beijing urban expansion}

In the training run of the LTM, the MSE (mean square error) started at around 0.0337 and by 4000 cycles diminished to values between 0.026 and 0.027 . We halted the training at 11,000 cycles, when the MSE was 0.02632. According to Eq. (6), the PCM of the model was about $60.98 \%$ accurate (Fig. 5). Based on this level of accuracy over such a large area $\left(16,410.54 \mathrm{~km}^{2}\right)$; we consider the model to be satisfactory.

After the ANN was successfully trained and calibrated, we used the biases and weights to forecast future urban expansion. However, before spatially modeling the urban expansion, i.e., which areas will be occupied, we needed to know the overall amount of expansion in Beijing. Because we aim to predict the locations occupied by expansion over the 15 years following the period covered by our baseline data, i.e., until 2020, we used the amount, $1650 \mathrm{~km}^{2}$, of Beijing urban land forecast for 2020 in by an official planning document (BMICPD et al., 2004). Thus, during 2005-2020, urban areas are expected to expand by $304.75 \mathrm{~km}^{2}$, at an average rate of $20.32 \mathrm{~km}^{2} /$ year. This expansion speed is close to that of $1995-2000$ $\left(21.89 \mathrm{~km}^{2} /\right.$ year$)$. On the basis of the 2005 land use map, we developed predictor maps of the spatial distribution of urban areas in 2020 (as shown in Fig. 6). We found that urban expansion will not be concentrated around the central urban area. On the contrary, it will mainly be distributed in Fangshan, Daxing, Changping and
Shunyi, accounting for $24.97 \%, 14.27 \%, 11.37 \%$ and $12.53 \%$ of the total, respectively.

\subsection{The farmland quality lost by urban expansion}

For the periods 1986-1995, 1995-2000, 2000-2005 and 2005-2020, we found the IHC values to be 2.21, 1.57, 1.99 and 1.10 , respectively (Table 2 ). The relative consumption of HQF by urban expansion is thus substantial. However, the relative consumption of HQF seems to decrease as time progresses. In contrast, the consumption of medium-quality farmland steadily increases from $70.93 \%$ to $80.50 \%$ over the four periods. The consumption of low-quality farmland, rather than having a clear trend, fluctuates over the four periods.

The changes over time in the consumption of HQF likely related to the spatial pattern of urban expansion (Fig. 7). In the first stage (1986-1995), farmland loss through urban expansion presented a distinct annulus around the central city, where a great deal of HQF was concentrated. In the following stage (1995-2000), the annulus feature of farmland loss by expansion became fuzzy, as farmland loss in the outer suburban areas became considerable. In the third stage (2000-2005), farmland loss was substantial both around the central city and in the outer suburban areas. In the last, ongoing stage (2005-2020), the farmland loss is not considerable around the central city, whereas it is remarkable in the outer northeast and 


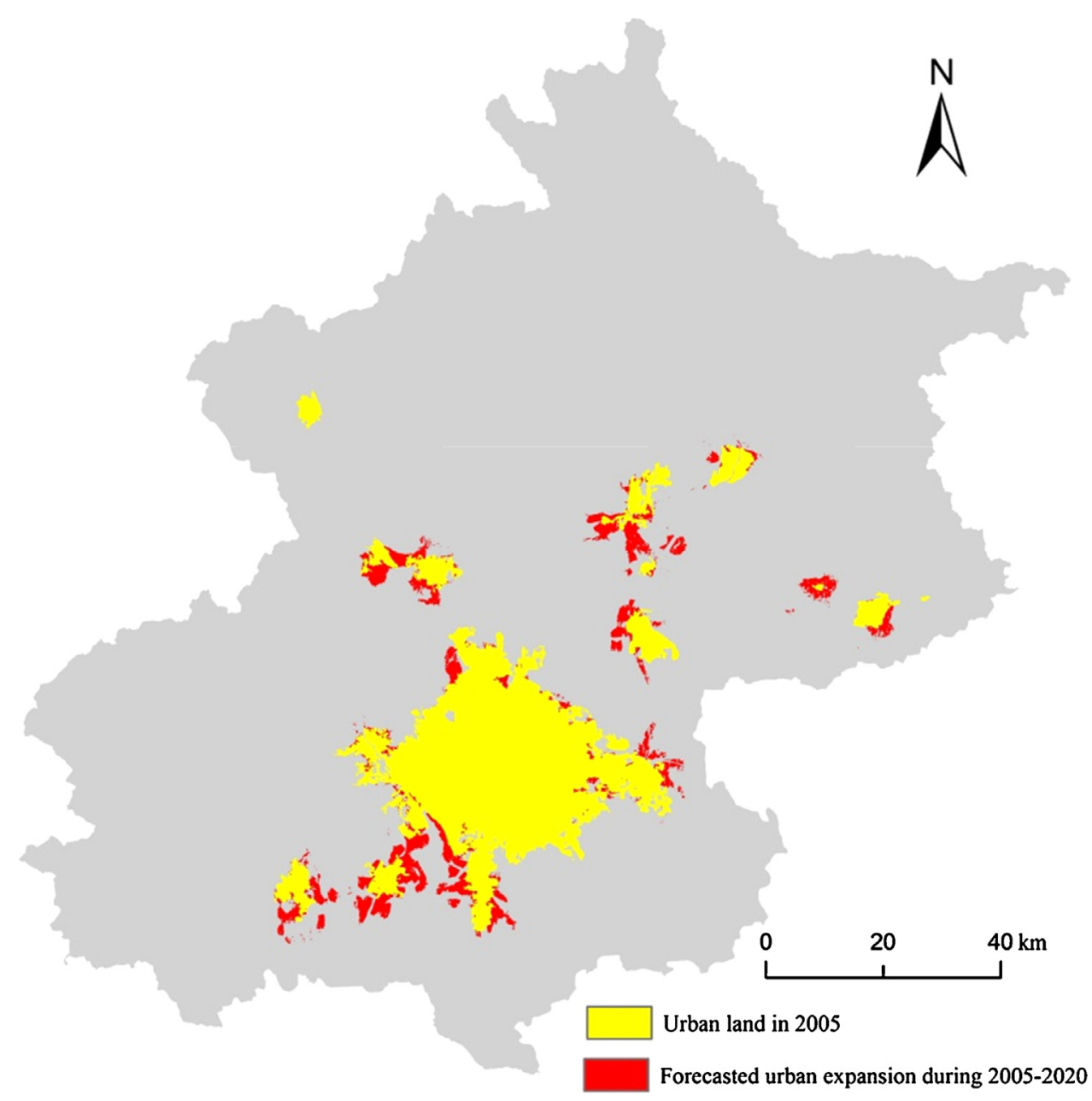

Fig. 6. Urban area in 2020 forecasted by LTM.

southwest suburban regions; thus, rather than forming an annulus, the pattern of farmland loss is more scattered.

\section{Discussion}

\subsection{Why urban expansion usually preferentially occupies $H Q F$}

We found that urban expansion in Beijing prefers to occupy HQF for several reasons. First, topography determines the spatial distribution of both urban expansion and HQF. Flatter areas are preferred for urban development, as they are more suitable for infrastructure, housing construction and population concentration, but they also feature $\mathrm{HQF}$, as flatter land is more suitable for large scale-crop plantation. Thus, the ratio of the slope score of HQF consumed by urban expansion to total farmland was 1.90 (Fig. 8).

Second, water resources are vital factors for both human habitation and growing crops. Thus, human settlement (both urban and rural) prefers to expand along the water bodies for the convenience of taking water, while farmland quality near water bodies is usually high because of excellent irrigation conditions. The ratio of the irrigation guarantee rate score of the HQF consumed by urban expansion to that of total farmland was thus 1.22. Lastly, distance to urban areas substantially influence both the areas preferred for urban expansion and the soil profile. The soil profile can affect farmland quality by determining the storage, holding and provision of soil water and nutrients. One of the factors influencing the soil profile is the length of time the land has been farmed. In general, better soil profiles are associated with longer farming times. The farmland around urban areas will have been cultivated the longest, due to its closeness to urban areas, but this closeness is also an important factor shaping urban expansion. However, the soil organic matter, effective soil thickness and soil texture do not show significant positive correlations with proximity to urban areas.

\subsection{Comparisons of the HQF consumption between Beijing and other cities}

Beijing's consumption of HQF is not a unique case worldwide. Thus, Imhoff et al. (1998) showed that the best soils are the first victims of urban sprawl in the U.S. In the municipalities of Rome and Fiumicino, Italy, urban growth has consumed high-quality soil types in larger proportions than low-quality soil types (Salvati, 2013). Moreover, about half of the more than $12,000 \mathrm{~km}^{2}$ of land occupied by expansion of cities and towns in Canada during 1971-1996 had been HQF (Francis et al., 2012).

Siebielec et al. (2010) assessed the consumption of HQF by urban expansion in seven cities in Central Europe between 1990-1992 and 2006-2007. They found that HQF (in terms of quality) was effectively protected in Bratislava by requiring payment of a substantial fee for their consumption. However, urban expansion in Vienna, Wroclaw, Prague and Salzburg preferentially consumed HQF. The occupancy of the most valuable soils in Stuttgart and Milan was proportional to their shares of total area.

Notably, this other research, unlike our present study, generally just uses soil quality rather than any measure of overall land quality, to assess HQF loss. This, more narrowly focused, approach 


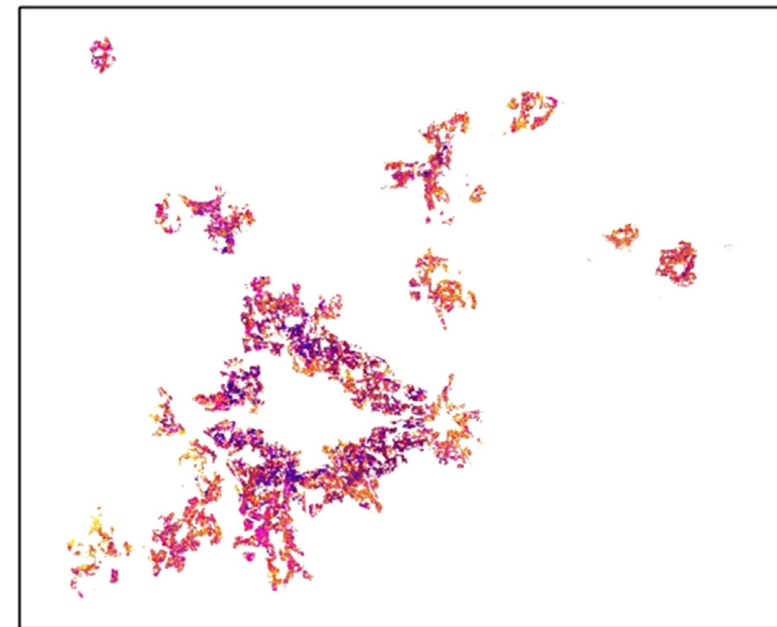

Farmland quality rank during 1986-2020

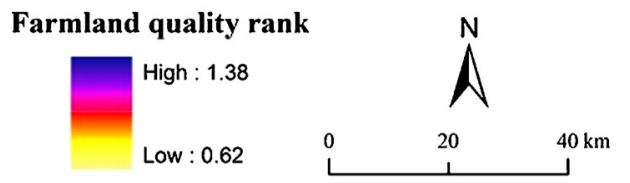

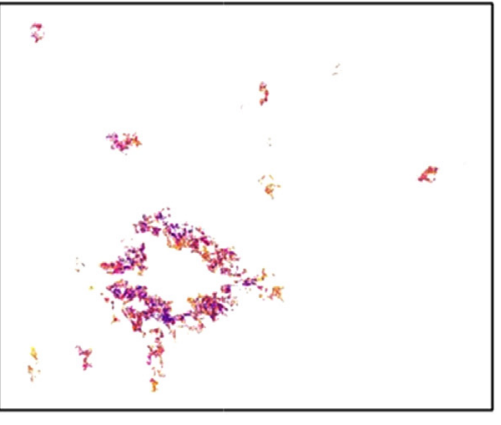

Farmland quality rank during 1986-1995

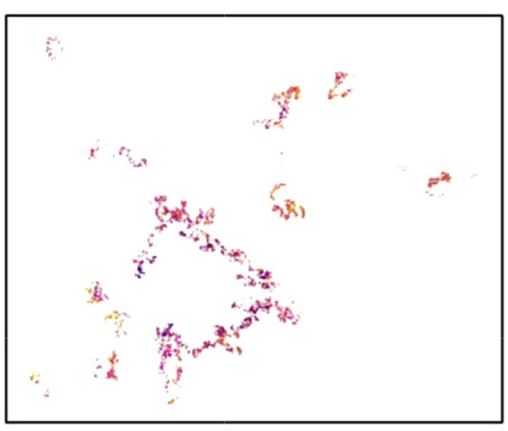

Farmland quality rank during 2000-2005

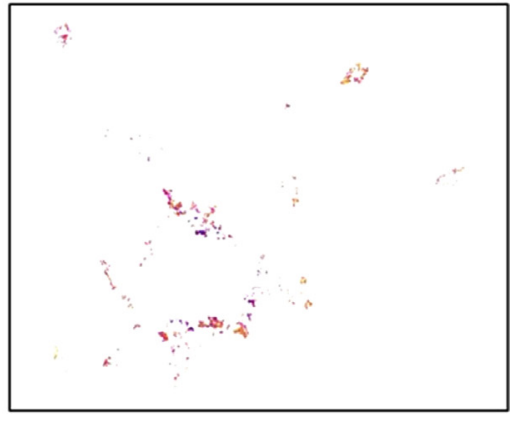

Farmland quality rank during $1995-2000$

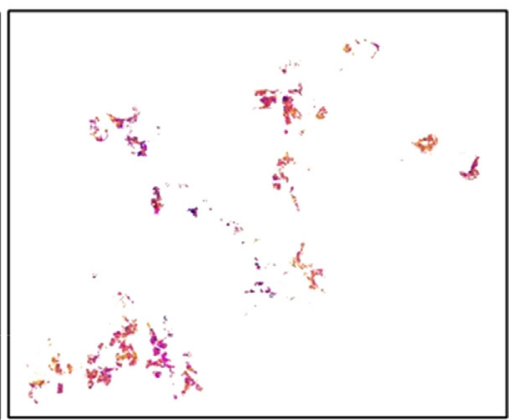

Farmland quality rank during 2005-2020

Fig. 7. Farmland quality lost by urban expansion during 1986-2020.

prevents a more thorough exploration of the underlying reasons for preferential HQF consumption by urban expansion.

\subsection{Policy implications for the protection of $\mathrm{HQF}$}

$\mathrm{HQF}$ in China is very precious. Although the farmland there occupies $13583.5 \times 10^{4}$ hectare, the most productive farmland accounted for only $2.67 \%$ of the total as of 2009 (DLUA et al., 2009). Moreover, although productivity of such farmland can reach $22,500 \mathrm{~kg} /$ hectare, it ranges downward to $1500 \mathrm{~kg} /$ hectare (DLUA et al., 2009; Song and Pijanowski, 2014). Thus, losing HQF is likely to significantly magnify the grain production loss resulting from farmland loss. Once high-quality farmland is occupied by urban expansion, the destroyed soil is impossible to be restored, due to soil sealing, meaning that the high-quality farmland loss by urban expansion will be permanent.

Effective policies should be adopted to protect the HQF from urban expansion. Of the previously mentioned international cases, the only one successful in controlling HQF loss was in Bratislava, where the transformation of HQF to other land-use types incurs

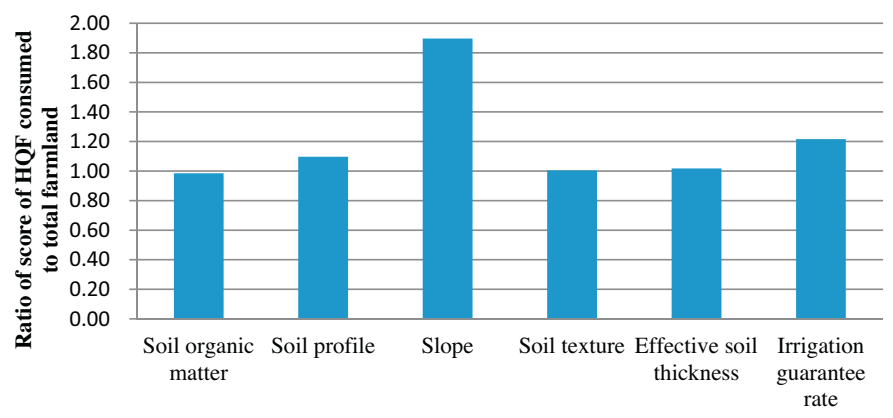

Fig. 8. Ratios of scores of high-quality farmland consumed by urban expansion to total farmland mandatory payment. The protection of HQF in China could similarly establish a special payment system for the occupation of HQF.

We found that the pattern of scattered urban expansion could mitigate HQF loss compared to central expansion pattern. Therefore, to promote HQF protection, China should limit overexpansion of central urban areas in mega-city regions and encourage development of decentralized city groups and satellite cities.

Finally, urban construction should be encouraged in hilly areas averting some loss of HQF. In western China urban development has already occurred in hilly areas of several cities, arousing great interest elsewhere in the world (Li et al., 2014; Liu and Li, 2014).

\section{Conclusions}

This study examined urban expansion over the past two decades (1986-2005) and in the next 15 years (2005-2020) by using the LTM model. Our study found the rates of urban expansion in Beijing to be $48.97 \mathrm{~km}^{2} /$ year, $21.89 \mathrm{~km}^{2} /$ year, $62.30 \mathrm{~km}^{2} /$ year and $20.32 \mathrm{~km}^{2} /$ year, respectively, during the periods $1986-1995$, 1995-2000, 2000-2005 and 2005-2020. The indicator we developed to assess the relative consumption of HQF by urban expansion shows values of $2.21,1.57,1.99$ and 1.10 for these four periods, respectively. Thus, although urban expansion in Beijing has preferred to occupy HQF, this preference seems to have been decreasing.

Urban expands preferentially in flat areas and areas close to water bodies, but these attributes also contribute to farmland quality. Moreover, farmland close to urban areas usually has a long farming history, with a better soil profile, but, due to its proximity, is more easily encroached upon by urban expansion. The overlapping spatial distributions of urban expansion and three attributes associated with $\mathrm{HQF}$, i.e. flat topography and distances to urban areas and rivers, determined the relative HQF consumption by urban expansion.

To mitigate the loss of HQF, we argue that the overexpansion of central urban areas in mega-city regions should be limited, while 
instead encouraging the development of decentralized groups and satellite cities. A special payment system for the occupation of HQF should be established in order to inhibit. Additionally, urban construction should be encouraged in hilly regions, to take pressure off flat areas associated with HQF.

\section{Acknowledgments}

This work was supported by National Key Basic Research Program of China (973 Program) (grant no. 2015CB452702), the National Natural Science Foundation of China (grant no. 41201599, 41171079 and 41001108) and China Clean Development Mechanism Fund (grant no. 2031202400003).

\section{References}

Angel, S., Parent, J., Civco, D.L., Blei, A., Potere, D., 2011. The dimensions of global urban expansion: estimates and projections for all countries, 2000-2050. Progress Plan. 75, 53-107.

Aspinall, R., 2004. Modelling land use change with generalized linear models-a multi-model analysis of change between 1860 and 2000 in Gallatin Valley, Montana. J. Environ. Manag. 72, 91-103.

Batisani, N., Yarnal, B., 2009. Urban expansion in Centre County, Pennsylvania: spatial dynamics and landscape transformations. Appl. Geogr. 29, 235-249.

Beijing Municipal Institute of City Planning \& Design (BMICPD), China Academy of Urban Planning (CAUP), Urban Planning and Design Institute (UPDI), TsingHua University, 2004. The General Urban Planning in Beijing (2004-2020). Beijing Municipal Commission of Urban Planning, Beijing, China.

Beinroth, F.H., Eswaran, H., Reich, P.F., 2001. Land quality and food security in Asia. Response to Land Degradation, pp. 83-97.

Chen, J., 2007. Rapid urbanization in China: a real challenge to soil protection and food security. Catena 69,1-15.

Chen, L.M., Zhang, G.L., Effland, W.R., 2011. Soil characteristic response times and pedogenic thresholds during the 1000 -year evolution of a paddy soil chronosequence. Soil Sci. Soc. Am. J. 75, 1807-1820.

Cheng, H.Q., Masser, I., 2003. Urban growth pattern modeling: a case study of Wuhan city, PR China. Landsc. Urban Plan. 62, 199-217.

Deng, X.Z., Huang, J.K., Rozelle, S., Uchida, E., 2010. Economic growth and the expansion of urban land in China. Urban Stud, 47, 813-843.

Department of Land Use and Administration (DLUA), China Land Surveying and Planning Institute (CLSPI), Land Consolidation \& Rehabilitation Center of the Ministry of Land and Resources (LCRC. of MLRC), 2009. The Investigation and Evaluation of the Quality Grade of China's Agricultural (Cultivated) Land. MLRC, Beijing, China.

Dubovyk, O., Sliuzas, R., Flacke, J., 2011. Spatio-temporal modelling of informa settlement development in Sancaktepe district, Istanbul, Turkey. ISPRS J. Photogramm. Remote Sens. 66, 235-246.

Dumanski, J., 1997. Criteria and indicators for land quality and sustainable land management. ITC J. 3/4, 216-222.

Dumanski, J., Pieri, C., 2000. Land quality indicators: research plan. Agric. Ecosyst. Environ. 81, 93-102.

Eswaran, H., Bienforth, F.H., Reich, P.F., 2003. A global assessment of land quality. In: Wiebe (Ed.), Land quality, agricultural productivity and food security: Biophysical processes and economic choices at local, regional and global levels. Edward Elgar, Northampton, MA, USA, pp. 112-132.

Food and Agriculture Organization of the United Nations (FAO), 1997. Land quality indicators and their use in sustainable agriculture and rural development: Proceedings of the Workshop. Food and Agriculture Organization of the United Nations, Rome, Italy.

Food Agriculture Organization of the United Nations (FAO), 1977. A Framework for Land Evaluation. International Institute for Land Reclamation and Improvement, Wageningen, Netherlands.

Francis, C.A., Hansen, T.E., Fox, A.A., Hesje, P.J., Nelson, H.E., Lawseth, A.E., English, A., 2012. Farmland conversion to non-agricultural uses in the US and Canada: current impacts and concerns for the future. Int. J. Agric. Sustain. 10, 8-24.

Guttikunda, S.K., Carmichael, G.R., Calori, G., Eck, C., Woo, J.H., 2003. The contribution of megacities to regional sulfur pollution in Asia. Atmos. Environ. 37, 11-22.

He, C.Y., Okada, N., Zhang, Q.F., Shi, P.J., Zhang, J.S., 2006. Modeling urban expansion scenarios by coupling cellular automata model and system dynamic model in Beijing, China. Appl. Geogr. 26, 323-345.

Hu, Z.Y., Lo, C.P., 2007. Modeling urban growth in Atlanta using logistic regression. Comput. Environ. Urban Syst. 31, 667-688.

Jiang, L., Deng, X.Z., Seto, K.C., 2012. Multi-level modeling of urban expansion and cultivated land conversion for urban hotspot counties in China. Landsc. Urban Plan. 108, 131-139.

Khoo, K.L., Tan, H., Liew, Y.M., Deslypere, J.P., Janus, E., 2003. Lipids and coronary heart disease in Asia. Atherosclerosis 169, 1-10.

Kim, D.S., Mizuno, K., Kobayashi, S., 2003. Analysis of urbanization characteristics causing farmland loss in a rapid growth area using GIS and RS. Paddy Water Environ. 1, 189-199.
Kong, F.H., Yin, H.W., Nakagoshi, N., James, P., 2012. Simulating urban growth processes incorporating a potential model with spatial metrics. Ecol. Indic. 20, 82-91.

Lee, D., Choe, H., 2011. Estimating the impacts of urban expansion on landscape ecology: forestland perspective in the greater Seoul metropolitan area. J. Urban Plan. Dev. (ASCE) 137, 425-437.

Li, P.Y., Qian, H., Wu, J.H., 2014. Accelerate research on land creation. Nature 510, 29-31.

Liu, J.Y., Liu, M.L., Tian, H.Q., Zhuang, D.F., Zhang, Z.X., Zhang, W., Tang, X.M., Deng X.Z., 2005. Spatial and temporal patterns of China's cropland during 1990-2000: an analysis based on Landsat TM data. Remote Sens. Environ. 98, 442-456.

Liu, Y.S., Zhang, Y.Y., Guo, L.Y., 2010. Towards realistic assessment of cultivated land quality in an ecologically fragile environment: a satellite imagery-based approach. Appl. Geogr. 30, 271-281.

Liu, Y.S., Li, Y.H., 2014. China's land creation project stands firm. Nature 511, 410-410

Lu, Q.S., Liang, F.Y., Bi, X.L., Duffy, R., Zhao, Z.P., 2011. Effects of urbanization and industrialization on agricultural land use in Shandong Peninsula of China. Ecol. Indic. 11, 1710-1714.

Imhoff, M.L., Lawerence, W.T., Stutzer, D., Elvidge, C., 1998. Assessing the impact of urban sprawl on soil resources in the United States using nighttime "city lights" satellite images and digital soils maps. In: Perspectives on the Land Use History Of North America: A Context for Understanding our Changing Environment. U.S. Geological Survey, Washington, D.C., USA, pp. 13-22 (USGS/BRD/BSR-19980003).

Pijanowski, B.C., Brown, D.G., Shellito, B.A., Manik, G.A., 2002. Using neural networks and GIS to forecast land use changes: a land transformation model. Comput. Environ. Urban Syst. 26, 553-575.

Pijanowski, B.C., Pithadia, S., Shellito, B.A., Alexandridis, K., 2005. Calibrating a neura network-based urban change model for two metropolitan areas of the Upper Midwest of the United States. Int. J. Geogr. Inf. Sci. 19, 197-215.

Pijanowski, B.C., Tayyebi, A., Delavar, M.R., Yazdanpanah, M.J., 2009. Urban expansion simulation using geospatial information system and artificial neural networks. Int. J. Environ. Res. 3, 493-502

Pijanowski, B.C., Tayyebi, A., Doucette, J., Pekin, B.K., Braun, D., Plourde, J., 2014. A big data urban growth simulation at a national scale: Configuring the GIS and neural network based land transformation model to run in a high performance computing (HPC) environment. Environ. Model. Softw. 51, 250-268.

Rebele, F., 1994. Urban ecology and special features of urban ecosystems. Global Ecol. Biogeogr. Lett, 4, 173-187.

Sala, O.E., Chapin, F.S., Armesto, J.J., Berlow, E., Bloomfield, J., Dirzo, R., HuberSanwald, E., Huenneke, L.F., Jackson, R.B., Kinzig, A., Leemans, R., Lodge, D.M., Mooney, H.A., Oesterheld, M., Poff, N.L., Sykes, M.T., Walker, B.H., Walker, M., Wall, D.H., 2000. Biodiversity-global biodiversity scenarios for the year 2100 . Science 287, 1770-1774.

Seto, K.C., Fragkias, M., Guneralp, B., Reilly, M.K., 2011. A meta-analysis of global urban land expansion. PLOS One 6 (Article ID e23777).

Seto, K.C., Guneralp, B., Hutyra, L.R., 2012. Global forecasts of urban expansion to 2030 and direct impacts on biodiversity and carbon pools. Proc. Natl. Acad. Sci. U. S. A. 109, 16083-16088.

Shahbaz, M., Sbia, R., Hamdi, H., Ozturk, I., 2014. Economic growth, electricity consumption, urbanization and environmental degradation relationship in United Arab Emirates. Ecol. Indic. 45, 622-631.

Siebielec, G., Lopatka, A., Stuczynski, T., Kozak, M., Gluszynska, M., Koza, J., Zurek A., Korzeniowska-Puculek, R., 2010. Assessment of Soil Protection Efficiency and Land Use Change. Institute of Soil Science and Plant Cultivation, State Research Institute, Pulawy, Poland, pp. 1-42.

Song, W., 2014. Decoupling cultivated land loss by construction occupation from economic growth in Beijing. Habitat Int. 43, 198-205.

Song, W., Chen, B.M., Zhang, Y., Wu, J.Z., 2012. Establishment of rural housing land standard in China. Chin. Geogr. Sci. 22, 483-495.

Song, W., Liu, M.L., 2014. Assessment of decoupling between rural settlement area and rural population in China. Land Use Policy 39, 331-341.

Song, W., Pijanowski, B.C., 2014. The effects of China's cultivated land balance program on potential land productivity at a national scale. Appl. Geogr. 46, 158-170.

Su, S.L., Ma, X.Y., Xiao, R., 2014. Agricultural landscape pattern changes in response to urbanization at ecoregional scale. Ecol. Indic. 40, 10-18.

Su, Z.M., Zhang, R.Z., Qiu, J.X., 2011. Decline in the diversity of willow trunk-dwelling weevils (Coleoptera: Curculionoidea) as a result of urban expansion in Beijing, China. J. Insect Conserv. 15, 367-377.

Tan, M.H., Li, X.B., Xie, H., Lu, C.H., 2005. Urban land expansion and arable land loss in China-a case study of Beijing-Tianjin-Hebei region. Land Use Policy 22, $187-196$.

Tang, J.M., 2011. Modeling urban landscape dynamics using subpixel fractions and fuzzy cellular automata. Environ. Plan. B Plan. Design 38, 903-920.

Targulian, V.O., Krasilnikov, P.V., 2007. Soil system and pedogenic processes: selforganization, time scales, and environmental significance. Catena 71, 373-381.

Turner, B.L., 1994. Local faces, global flows-the role of land-use and land-cover in global environmental change. Land Degrad. Rehabil. 5, 71-78.

United Nations, 2012. World Urbanization Prospects the 2011 Revision. United Nations, New York.

Van Delm, A., Gulinck, H., 2011. Classification and quantification of green in the expanding urban and semi-urban complex: application of detailed field data and IKONOS-imagery. Ecol. Indic. 11, 52-60.

Van Metre, P.C., Mahler, B.J., 2005. Trends in hydrophobic organic contaminants in urban and reference lake sediments across the United States, 1970-2001. Environ. Sci. Technol. 39, 5567-5574. 
Verburg, P.H., Soepboer, W., Veldkamp, A., Limpiada, R., Espaldon, V., Mastura, S.S.A 2002. Modeling the spatial dynamics of regional land use: the CLUE-S model. Environ. Manag. 30, 391-405.

Verburg, P.H., Veldkamp, A., Fresco, L.O., 1999. Simulation of changes in the spatial pattern of land use in China. Appl. Geogr. 19, 211-233.

Wang, Q.S., Yuan, X.L., Zhang, J., Mu, R.M., Yang, H.C., Ma, C.Y., 2013. Key evaluation framework for the impacts of urbanization on air environment-a case study. Ecol. Indic. 24, 266-272.

Wang, S.J., Ma, H.T., Zhao, Y.B., 2014. Exploring the relationship between urbanization and the eco-environment-a case study of Beijing-Tianjin-Hebei region. Ecol. Indic. 45, 171-183.
Wu, F.L., Yeh, A.G.O., 1997. Changing spatial distribution and determinants of land development in Chinese cities in the transition from a centrally planned economy to a socialist market economy: a case study of Guangzhou. Urban Stud. 34 1851-1879.

Ye, Y.Y., Zhang, H.G., Liu, K., Wu, Q.T., 2013. Research on the influence of site factors on the expansion of construction land in the Pearl River Delta, China: by using GIS and remote sensing. Int. J. Appl. Earth Obs. Geoinf. 21, 366-373.

Zhong, T.Y., Huang, X.J., Zhang, X.Y., Wang, K., 2011. Temporal and spatial variability of agricultural land loss in relation to policy and accessibility in a low hilly region of southeast China. Land Use Policy 28, 762-769. 